\title{
A Note on Kumaraswamy Exponentiated Rayleigh distribution
}

\author{
Nasr Ibrahim Rashwan \\ Faculty of Commerce - Tanta University \\ Tanta-Egypt \\ nasrrashwan@yahoo.com
}

Received 18 August 2015

Accepted 28 April 2016

\begin{abstract}
In this paper, a new four parameter continuous distribution, called the Kumaraswamy Rayleigh (KW-ER) distribution is proposed and studied. Some mathematical properties are presented and discussed, these properties involve expansions for the cumulative and density functions, skewness and kurtosis based on the quantile function and explicit expressions for the moments and generating function. The density function of the order statistics and obtain their moments are provided. An explicit expression for Renyi entropy is obtained. The method of maximum likelihood is used for estimating the distribution parameters and the observed information matrix is derived. A data set is used to illustrate the application of the new distribution.
\end{abstract}

Keywords : Kumaraswamy exponentiated Rayleigh distribution ; quantile function ; moments generating function; order statistics; maximum likelihood estimation .

\section{Introduction}

The Two-Parameter exponentiated Rayleigh distribution has been widely used especially in the modeling of lifetime data and reliability. It provides a statistical model which has a wide variety of application in many areas and the main advantage is its ability in context of lifetime data among other distributions. Also, it provides a rich family of specific distributions that have widespread application in many disciplines. Members of this family include the Rayleigh distribution, the half-normal distribution; the Maxwell distribution and the chi-distribution (see Shankar and Kumar 2014).

Burr (1942) introduced twelve different forms of cumulative distribution functions for modeling lifetime data. Among those distributions, Burr Type X (exponentiated Rayleigh) and Burr Type XII are the most popular ones. Many authors considered different aspects of the Burr Type X, See, for example, Sartawi and Abu-Salih (1991), Ragab (1998), Surles and Padgett (2005), Kundu and Ragab (2005), Voda (2007) and Ragab and Madi (2009).

The exponentiated Rayleigh (ER) distribution can be defined by raising the distribution function of a rayleigh distribution to a positive power. Thus, the random variable $\mathrm{X}$ with ER distribution has the following cumulative distribution function (cdf).

$$
\mathrm{G}(\mathrm{x} ; \lambda, \theta)=\left(1-\mathrm{e}^{-(\lambda \mathrm{x})^{2}}\right)^{\theta} ; \mathrm{x}>0 \quad \lambda, \lambda, \theta>0
$$

and the probability density function (pdf) corresponding to eq.(1) is given by 


$$
\mathrm{g}(\mathrm{x} ; \lambda, \theta)=2 \theta \lambda^{2} \mathrm{x} \mathrm{e}^{-(\lambda \mathrm{x})^{2}}\left(1-\mathrm{e}^{-(\lambda \mathrm{x})^{2}}\right)^{\theta-1} ; \mathrm{x}, \lambda, \theta>0
$$

where $\theta$ and $\lambda$ are the shape and scale parameters.

The distribution by kumaraswamy (1980) is not very common among statisticians and has been little explored in the literature. Its cumulative distribution function (for $0<\mathrm{x}<1)$ is $\mathrm{F}(\mathrm{x} ; \mathrm{a}, \mathrm{b})=1-\left(1-\mathrm{x}^{\mathrm{a}}\right)^{\mathrm{b}}$ where $a>0$ and $b>0$ are shape parameters, and the density function has a simple form $f(x ; a, b)=a b x^{a-1}\left(1-x^{a}\right)^{b-1}$, which can be unimodal increasing, decreasing or constant, depending on the values of its parameters. Recently, Jones (2009) explored the background and genesis of this distribution, and more importantly, made clear some similarities and differences between the beta and kumaraswamy distributions.

If $\mathrm{G}(\mathrm{x})$ is the baseline cdf of a random variable $\mathrm{X}$, Cordeiro and de Castro (2010), defined the cdf of the KW-G distribution by

$$
F(x)=1-\left[1-G(x)^{a}\right]^{b}
$$

and the pdf corresponding to eq.(3) takes the form

$$
f(x)=a b g(x) G(x)^{a-1}\left[1-G(x)^{a}\right]^{b-1}
$$

where $\mathrm{a}>0$ and $\mathrm{b}>0$ are two additional parameters to the $\mathrm{G}$ distribution. Several generalized distributions from eq.(4) have been defined and investigated in the literature including a new generalized kumaraswamy distribution by Carrasco et al (2010), the kumaraswamy weibull distribution by cordeiro et al (2010), the kumaraswamy generalized Gamma distribution by de Pascoa et al (2011), the kumaraswamy Parato distribution by Bourguignon et al (2012), The kumaraswamy generalized half-normal distribution by Cordeiro et al (2012), some new results for the kumaraswamy modified weibull distribution by Cordeiro et al (2014) and statistical properties of kumaraswamy exponentiated Lamax distribution by El-Batal and Kareem (2014).

This paper is organized as follows. In section 2, research proposes and define the (KW-ER) distribution and provide expansions for its cumulative and density functions of this distribution. Some of mathematical properties of this distribution is considered in section 3. The density function of order statistics and obtain their moments are provided in section 4. The Renyi entropy is derived in section 5. Maximum likelihood estimation is performed and the observed information matrix is determined and provide with application of the KW-ER distribution in section 6. Finally, some conclusions are addressed in section 7.

\section{The KW-ER distribution}

If $\mathrm{G}(\mathrm{x} ; \lambda, \theta)$ is exponentiated rayleigh distribution with parameters $\lambda$ and $\theta$, Then eq.(3) yields the KW-ER cumulative distribution for $\mathrm{X}>0$

$$
\mathrm{F}(\mathrm{x} ; \lambda, \theta, \mathrm{a}, \mathrm{b})=1-\left[1-\left(1-\mathrm{e}^{-(\lambda \mathrm{x})^{2}}\right)^{\theta \mathrm{a}}\right]^{\mathrm{b}}
$$

and the corresponding pdf is defined as

$$
\mathrm{f}(\mathrm{x} ; \lambda, \theta, \mathrm{a}, \mathrm{b})=2 \mathrm{ab} \theta \lambda^{2} \mathrm{xe}^{-(\lambda \mathrm{x})^{2}}\left(1-\mathrm{e}^{-(\lambda \mathrm{x})^{2}}\right)^{\theta \mathrm{a}-1}\left[1-\mathrm{e}^{-(\lambda \mathrm{x})^{2}}\right]^{\mathrm{b}-1} ; \mathrm{x}, \lambda, \theta, \mathrm{a}, \mathrm{b}>0
$$

where $\lambda$ is a scale parameter and the other positive parameters $a, b$ and $\theta$ are shape parameters. The reliability (survival) function, $\mathrm{R}(\mathrm{x})$, hazard rate function, $\mathrm{h}(\mathrm{x})$, reversed hazard rate function, $\mathrm{r}(\mathrm{x})$, and the cumulative hazard rate function, $\mathrm{H}(\mathrm{x})$, of KW-ER distribution are given by

$$
\begin{gathered}
\mathrm{R}(\mathrm{x})=1-\mathrm{F}(\mathrm{x} ; \lambda, \theta, \mathrm{a}, \mathrm{b})=\left[1-\left(1-\mathrm{e}^{-(\lambda \mathrm{x})^{2}}\right)\right]^{\theta} \mathrm{b} \\
\mathrm{h}(\mathrm{x})=\frac{\mathrm{f}(\mathrm{x} ; \lambda, \theta, \mathrm{a}, \mathrm{b})}{\mathrm{R}(\mathrm{x})}=\frac{2 \mathrm{ab} \theta \lambda^{2} \mathrm{x} \mathrm{e}^{-(\lambda \mathrm{x})^{2}}\left(1-\mathrm{e}^{-(\lambda \mathrm{x})^{2}}\right)^{\theta \mathrm{a}-1}}{1-\left(1-\mathrm{e}^{-(\lambda \mathrm{x})}\right)^{\theta \mathrm{a}}} \\
\begin{array}{c}
\text { Published by Atlantis Press } \\
\text { Copyright: the authors }
\end{array}
\end{gathered}
$$




$$
\mathrm{r}(\mathrm{x})=\frac{\mathrm{f}(\mathrm{x} ; \lambda, \theta, \mathrm{a}, \mathrm{b})}{\mathrm{F}(\mathrm{x} ; \lambda, \theta, \mathrm{a}, \mathrm{b})}=\frac{2 \mathrm{ab} \theta \lambda^{2} \mathrm{x} \mathrm{e}^{-(\lambda \mathrm{x})^{2}}\left(1-\mathrm{e}^{-(\lambda \mathrm{x})^{2}}\right)^{\theta \mathrm{a}-1}\left[1-\left(1-\mathrm{e}^{-(\lambda \mathrm{x})^{2}}\right)^{\theta \mathrm{a}}\right]^{\mathrm{b}-1}}{1-\left[1-\left(1-\mathrm{e}^{-(\lambda \mathrm{x})^{2}}\right)^{\theta \mathrm{a}}\right]^{\mathrm{b}}}
$$

and

$$
H(x)=-\ln R(x)=-\ln \left[1-\left(1-\mathrm{e}^{-(\lambda x)^{2}}\right)^{\theta a}\right]^{b}
$$

respectively. We notice that the following distributions are special cases of the KW-ER distribution function.

- if $\theta=1$, eq.(6) reduces to the kumaraswamy rayleigh distribution function.

- if $\mathrm{a}=\mathrm{b}=1$, we get the exponentiated rayleigh distribution function.

- $\quad$ if $\mathrm{a}=\mathrm{b}=\theta=1$, eq.(6) gives the rayleigh distribution function.

\subsection{Expansion for the cumulative and density functions}

Here, we present simple expansions for the KW-ER cumulative distribution, By using the generalized binomial theorem if $\mathrm{v}$ is a positive and $|\mathrm{a}|<1$, Then

$$
(1-\mathrm{a})^{\mathrm{v}-1}=\sum_{\mathrm{i}=0}^{\infty}(-1)^{\mathrm{i}}\left(\begin{array}{c}
\mathrm{v}-1 \\
\mathrm{i}
\end{array}\right) \mathrm{a}^{\mathrm{i}}
$$

eq.(5) becomes

and eq.(6) becomes

$$
\mathrm{F}(\mathrm{x} ; \lambda, \theta, \mathrm{a}, \mathrm{b})=1-\sum_{i=o}^{\infty}(-1)^{i}\left(\begin{array}{l}
b \\
i
\end{array}\right)\left(1-e^{-(\lambda x)^{2}}\right)^{\theta a i}
$$

$$
\mathrm{f}(\mathrm{x} ; \lambda, \theta, \mathrm{a}, \mathrm{b})=\sum_{i=o}^{\infty} W_{j} S(x ; \lambda(j+1))
$$

where

$$
\mathrm{W}_{\mathrm{j}}=\frac{\mathrm{ab} \theta}{(\mathrm{j}+1)} \sum_{\mathrm{i}=\mathrm{o}}^{\infty}(-1)^{\mathrm{i}+\mathrm{j}}\left(\begin{array}{c}
\mathrm{b}-1 \\
\mathrm{i}
\end{array}\right)\left(\begin{array}{c}
\theta \mathrm{a}(\mathrm{i}+1)-1 \\
\mathrm{j}
\end{array}\right)
$$

and $s(x, \lambda(j+1))$ denotes the rayleigh function with parameter $\lambda(j+1)$. Thus, the KW-ER density function can be expressed as an infinite linear combination of rayleigh densities. Also, $f(x ; \lambda, \theta, a, b)$ can be write as follows:

$$
f(x, \lambda, \theta, a, b)=b \sum_{i=0}^{\infty} \frac{(-1)^{i}\left(\begin{array}{c}
b-1 \\
i
\end{array}\right)}{(i+1)} g(x ; \lambda, \theta a(i+1))
$$

Where $\mathrm{g}(\mathrm{x} ; \lambda, \theta \mathrm{a}(\mathrm{i}+1))$ denotes the exponentiated rayleigh density function with parameters $\lambda$ and $\theta \mathrm{a}(\mathrm{i}+1)$.

\section{Statistical properties of KW-ER distribution}

In this section, we discuss some of statistical properties of the KW-ER distribution, specifically, moments and generating function, as well as quantile function. 


\subsection{Moments}

Let $\mathrm{X}$ a random variable having the KW-ER distribution. Using eq.(10), the $\mathrm{r}^{\text {th }}$ moment about zero of $\mathrm{X}$ can be obtained as

$E\left(x^{r}\right)=\sum_{j=0}^{\infty} W_{j} \int_{0}^{\infty} x^{r} S(x ; \lambda(j+1)) d x$

Based on the transformation $y=(J+1)(\lambda x)^{2} \cdot y>0$

Then, $x=\frac{1}{\lambda}\left(\frac{y}{j+1}\right)^{1 / 2} \cdot d x=\left[y^{-1 / 2} d y / 2 \lambda(j+1)^{1 / 2}\right]$

The $E\left(x^{r}\right)=\frac{1}{\lambda^{r}} \sum_{j=o}^{\infty} \frac{\Gamma\left(\frac{r}{2}+1\right) W_{j}}{(j+1)^{r / 2}}$

Where $\Gamma$ (.) denotes the gamma function

The mean, variance, skewness and kurtosis can be obtained from eq.(12).

\subsection{Incomplete moments}

The answers to many important questions in economics require more than just knowing the mean of the distribution but its shape as well. This is obvious not only, in the study of econometrics but in other areas as well. The $\mathrm{r}^{\text {th }}$ incomplete moment of $\mathrm{x}$ by using eq.(10) is given by

$$
\begin{aligned}
M_{x}(Z) & =E\left(x^{r} \backslash x<Z\right) \\
& =\sum_{j=0}^{\infty} W_{j} \int_{0}^{Z} X^{r} s(x ; \lambda(j+1)) d x \\
& =\frac{1}{\lambda^{r}} \sum_{j=0}^{\infty} \frac{\Gamma_{I}\left(\frac{r}{2}+1,(j+1)(\lambda Z)^{2}\right) W_{j}}{(j+1)^{r / 2}}
\end{aligned}
$$

Where $\quad \Gamma_{\mathrm{I}}\left(\frac{\mathrm{r}}{2}+1,(\mathrm{j}+1)(\lambda \mathrm{Z})^{2}\right)=\int_{0}^{(\mathrm{j}+1)(\lambda \mathrm{Z})^{2}} \mathrm{y}^{\left(\mathrm{r} / 2^{+1)-1}\right.} \mathrm{e}^{-\mathrm{y}} \mathrm{dy}$

is generalized incomplete gamma function. The main application of the first incomplete moment refers to the Bonferroni and Lorenz curves. These curves are very useful in economics, reliability demography, insurance and medicine. A further application of the first incomplete moment is related to the mean residual life and the mean waiting time (See Tahir et al (2014)).

\subsection{Moments generating function}

Now, we can derive the moment generating function of the KW-ER distribution as follow:

$\mathrm{M}_{\mathrm{x}}(\mathrm{t})=\mathrm{E}\left(\mathrm{e}^{\mathrm{tx}}\right)=\sum_{\mathrm{j}=\mathrm{o}}^{\infty} \mathrm{W}_{\mathrm{j}} \int_{0}^{\infty} \mathrm{e}^{\mathrm{tx}} \mathrm{s}(\mathrm{x} ; \lambda(\mathrm{j}+1))$

Using Maclaurin's series expansion of $\mathrm{e}^{\mathrm{tx}}$, where

$$
\mathrm{e}^{\mathrm{tx}}=1+\frac{\mathrm{tx}}{1 !}+\frac{(\mathrm{tx})^{2}}{2 !}+\ldots=\sum_{\mathrm{r}=\mathrm{o}}^{\infty} \frac{(\mathrm{tx})^{\mathrm{r}}}{\mathrm{r} !}
$$

So, the moment generating function of the KW-ER distribution is given by 
$M_{x}(t)=\sum_{j=0}^{\infty} \sum_{r=0}^{\infty} \frac{(t)^{r}}{r !} \int_{0}^{\infty} x^{r} s(x ; \lambda(j+1)) d x$

Based on the transformation $y=(j+1)(\lambda x)^{2}$, we get

$$
M_{x}(t)=\sum_{r=0}^{\infty} \sum_{j=0}^{\infty} \frac{(t)^{r} \Gamma\left(\frac{r}{2}+1\right) W_{j}}{\lambda^{r} r !(j+1)^{r / 2}}
$$

In the same way, the factorial moment generating function of the KW-ER distribution becomes

$$
\mathrm{M}_{\mathrm{x}}(\ln \mathrm{t})=\mathrm{E}\left(\mathrm{e}^{\mathrm{x} \ln \mathrm{t}}\right)=\sum_{\mathrm{r}=\mathrm{o}}^{\infty} \sum_{\mathrm{j}=\mathrm{o}}^{\infty} \frac{(\ln \mathrm{t})^{\mathrm{r}} \Gamma(\mathrm{r} / 2+1) \mathrm{W}_{\mathrm{j}}}{\lambda^{\mathrm{r}} \mathrm{r} !(\mathrm{j}+1)^{\mathrm{r} / 2}}
$$

and the characteristic function of this distribution is given by

$$
\phi_{x}(t)=E\left(e^{i t x}\right)=\sum_{r=0}^{\infty} \sum_{j=0}^{\infty} \frac{(i t)^{r} \Gamma(r / 2+1) W_{j}}{\lambda^{r} r !(j+1)^{r / 2}}
$$

Where $i=\sqrt{-1}$ is the unit imaginary number.

\subsection{Quantile function}

The quantile function of $\mathrm{X}$ can be obtained by inverting eq.(5) as follows:

$$
\mathrm{Q}(\mathrm{u})=\frac{1}{\lambda}\left[-\ln \left[1-\left(1-(1-\mathrm{u})^{1 / \mathrm{b}}\right)^{1 / \theta \mathrm{a}}\right]\right]^{1 / 2}
$$

Simulating the KW-ER random variable is straight forward. Let $U$ be a uniform variable on the unit interval $[0,1]$. Thus, by means of the inverse transformation method, we consider the random variable $\mathrm{X}=\mathrm{Q}(\mathrm{u})$ follows eq. (6), i.e., $\mathrm{X} \sim \mathrm{KW}$-ER ( $\mathrm{a}, \mathrm{b}, \lambda, \theta$ ). By using $\mathrm{Q}(\mathrm{u})$, we can obtain the median, quantiles 25 and 75 by replacing $0.5,0.25$ and 0.75 in eq.(17) respectively.

\subsection{Skewness and Kurtosis}

The shortcomings of the classical kurtosis measure are well-known; (See Seier and Bonett (2003), Brys et al 2006). There are many heavy-tailed distributions for which this measure is infinite. So, it becomes uninformative precisely when it needs to be. Indeed, our motivation to use quantile-based measures stemmed from the nonexistence of classical kurtosis for many distributions. The effect of the shape parameters $a$ and $b$ on the skewness and kurtosis of the KW-ER distribution can be based on quantile measures. One of the earliest skewness measures to be suggested is the Bowley skewness (See Kenny and and Keeping 1962) defined by

$$
\mathrm{S}_{\mathrm{K}}=\frac{\mathrm{Q}(3 / 4)-2 \mathrm{Q}(1 / 2)+\mathrm{Q}(1 / 4)}{\mathrm{Q}(3 / 4)-\mathrm{Q}(1 / 4)}
$$

and the moors kurtosis (See Moors 1998) is based on actiles and is given by 


$$
\mathrm{K}_{\mathrm{u}}=\frac{\mathrm{Q}(7 / 8)-\mathrm{Q}(5 / 8)+\mathrm{Q}(3 / 8)-\mathrm{Q}(1 / 8)}{\mathrm{Q}(6 / 8)-\mathrm{Q}(2 / 8)}
$$

where $Q$ (.) represents the quantile function. The measures $S_{k}$ and $K_{u}$ are less sensitive to outlier values and they exist even for distributions without moments.

\section{Distribution of the order statistics}

Moments of order statistics play an important role in quality control testing and reliability, where a practitioner needs to predict the failure of future items based on the times of a few early failures. These predictors are often based on moments of order statistics. In this study, researcher derive closed form expression for the pdf of the $i^{\text {th }}$ order statistic $X_{i: n}$, say the density $f_{i, n}(X)$ of the $i^{\text {th }}$ order statistics, for $I=1,2$, $3, \ldots, \mathrm{n}$, in a random sample of size $\mathrm{n}$ from the KW-ER distribution is given by

$$
F_{i: n}(x)=\frac{f(x)}{B(i, n-i+1)}[F(x)]^{i-1}[1-F(x)]^{n-i}
$$

where $\mathrm{B}($.$) denotes the Beta function and \mathrm{f}($.$) and \mathrm{F}($.$) are the pdf and cdf of the KW-ER distribution$ respectively.

Substituting eq.(5) and eq.(6) in the above equation and using the generalized binomial series expansion; we obtain a useful expression for $\mathrm{f}_{\mathrm{i}: \mathrm{n}}(\mathrm{x})$ given by

$$
\mathrm{f}_{\mathrm{i}: \mathrm{n}}(\mathrm{x})=\sum_{\mathrm{r}=\mathrm{o}}^{\infty} \mathrm{C}_{\mathrm{i}: \mathrm{n}}^{(\mathrm{r})} \mathrm{s}(\mathrm{x} ; \lambda(\mathrm{r}+1))
$$

where

$\mathrm{C}_{\mathrm{i}: \mathrm{n}}^{(\mathrm{r})}=\frac{\mathrm{ab} \theta}{\mathrm{B}(\mathrm{i}, \mathrm{n}-\mathrm{i}+1)} \sum_{1=0}^{\infty} \sum_{\mathrm{m}=\mathrm{o}}^{\infty} \frac{(-1)^{1+\mathrm{m}+\mathrm{r}}}{(\mathrm{r}+1)}\left(\begin{array}{c}\mathrm{i}-1 \\ 1\end{array}\right)\left(\begin{array}{c}\mathrm{b}(\mathrm{l}+\mathrm{n}+1-\mathrm{i})-1 \\ \mathrm{~m}\end{array}\right)\left(\begin{array}{c}\theta \mathrm{a}(\mathrm{m}+1)-1 \\ \mathrm{r}\end{array}\right)$

and $\mathrm{s}(\mathrm{x}, \lambda(\mathrm{r}+1))$ denotes the rayleigh density function with parameter $\lambda(\mathrm{r}+1)$. Eq.(20) plays an important role in the derivation of the main properties of the KW-ER order statistics. For example, the $\mathrm{v}^{\text {th }}$ ordinary moment of $\mathrm{X}_{\mathrm{i}: \mathrm{n}}$ can be write as

$$
E\left(\mathrm{x}_{\mathrm{i}: \mathrm{n}}^{\mathrm{v}}\right)=\frac{1}{\lambda^{\mathrm{v}}} \sum_{\mathrm{r}=\mathrm{o}}^{\infty} \frac{\Gamma\left(\frac{\mathrm{v}}{2}+1\right) \mathrm{C}_{\mathrm{i}: \mathrm{n}}^{(\mathrm{r})}}{(\mathrm{r}+1)^{\mathrm{v} / 2}}
$$

The L-moments are analogous to the ordinary moments but can be estimated by linear combinations of order statistics. They exist whenever the mean of the distribution exists, even though some higher moments may not exist and are relatively robust to the effects of outliers. Based on the moments in eq.(21), we can derive explicit expressions for the L-moments of $\mathrm{X}$ as infinite weighted linear combinations of the means of suitable KW-ER distribution. Linear functions of expected order statistics can be defined by:

$\alpha_{\mathrm{m}+1}=\frac{1}{\mathrm{~m}+1} \sum_{\mathrm{k}=\mathrm{o}}^{\mathrm{m}}(-1)^{\mathrm{k}}\left(\begin{array}{c}\mathrm{m} \\ \mathrm{k}\end{array}\right) \mathrm{E}\left(\mathrm{x}_{\mathrm{m}+1-\mathrm{k}: \mathrm{m}+1}\right), \mathrm{m}=0,1,2, \ldots$

The first four L-moments are $\alpha_{1}=\mathrm{E}\left(\mathrm{X}_{1: 1}\right)$ ، $\alpha_{2}=\frac{1}{2} \mathrm{E}\left(\mathrm{X}_{2: 2}-\mathrm{X}_{1: 2}\right)$. $\alpha_{3}=\frac{1}{3} E\left[X_{3: 3}-2 X_{2: 3}+X_{1: 3}\right]$ and $\alpha_{4}=\frac{1}{4}\left[X_{4: 4}-3 X_{3: 4}+3 X_{2: 4}-X_{1: 4}\right]$.

We can easily obtain the $\alpha$ 's (L-moments) for $\mathrm{X}$ from eq.(21) with $\mathrm{v}=1$. 


\section{Renyi Entropy}

The entropy of a random variable $\mathrm{X}$ is a measure of uncertain variation. The Renyi entropy is defined as

$$
\mathrm{I}_{\mathrm{X} ; \mathrm{R}}(\delta)=\frac{1}{1-\delta} \operatorname{Ln}\left(\mathrm{I}_{\mathrm{X}}(\delta)\right),
$$

Where $\mathrm{I}_{\mathrm{X}}(\delta)=\int_{\mathrm{R}} \mathrm{f}^{\delta}(\mathrm{x}) \mathrm{dx} \quad \boldsymbol{\sigma} \delta>0$ and $\delta \neq 1$

For KW-ER a random variable we have

$\mathrm{I}_{\mathrm{X}}(\delta)=(2 \mathrm{ab} \theta)^{\delta} \lambda^{2 \delta} \int_{0}^{\infty} \mathrm{X}^{\delta} \mathrm{e}^{-\delta(\lambda \mathrm{x})^{2}}\left(1-\mathrm{e}^{-(\lambda \mathrm{x})^{2}}\right)^{\delta(\theta \mathrm{a}-1)}\left[1-\left(1-\mathrm{e}^{-(\lambda \mathrm{x})^{2}}\right)^{\theta \mathrm{a}}\right]^{\delta(\mathrm{b}-1)}$

Appling the binomial expansion twice in the last equation and integrating yields:

$$
\mathrm{I}_{\mathrm{x}}(\delta)=(\mathrm{ab} \theta)^{\delta}(2 \lambda) \sum_{\mathrm{i}=\mathrm{o}}^{\delta-1} \sum_{\mathrm{j}=\mathrm{o}}^{\infty} \frac{(-1)^{\mathrm{i}+\mathrm{j}}}{[\delta(\mathrm{j}+1)]^{\frac{\delta+1}{2}}}\left(\begin{array}{c}
\delta(\mathrm{b}-1) \\
\mathrm{i}
\end{array}\right)\left(\begin{array}{c}
\mathrm{a} \theta(\delta+\mathrm{i})-\delta \\
\mathrm{j}
\end{array}\right) \Gamma\left(\frac{\delta-1}{2}+1\right)
$$

Hence, the Renyi entropy becomes:

$$
\mathrm{I}_{\mathrm{X} ; \mathrm{R}}(\delta)=\frac{\delta \ln (\mathrm{ab} \theta)}{1-\delta}+\frac{\delta-1}{1-\delta} \ln (2 \lambda)+\frac{1}{1-\delta} \ln \sum_{\mathrm{i}=\mathrm{o}}^{\infty} \sum_{\mathrm{j}=\mathrm{o}}^{\infty} \frac{(-1)^{\mathrm{i}+\mathrm{j}}\left(\begin{array}{c}
\delta(\mathrm{b}-1) \\
\mathrm{i}
\end{array}\right)\left(\begin{array}{c}
\mathrm{a} \theta(\delta+\mathrm{i})-\delta \\
\mathrm{j}
\end{array}\right) \Gamma\left(\frac{\delta-1}{2}+1\right)}{[\delta(\mathrm{j}+1)]^{\frac{\delta+1}{2}}}
$$

\section{Estimation and Fisher information matrix}

The maximum likelihood estimation (MLE) is one of the most widely used estimation method for finding the unknown parameters. Let $\mathrm{x}_{1}, \mathrm{x}_{2}, \ldots, \mathrm{x}_{\mathrm{n}}$ be an independent random sample of size $\mathrm{n}$ from KW-ER distribution and let $\beta=(a, b, \theta, \lambda)^{\mathrm{T}}$ be the vector of unknown parameters. The log-likelihood function for the vector of parameters can be expressed as

$\mathrm{L}=\mathrm{n} \ln (2)+\mathrm{n} \ln (\mathrm{a})+\mathrm{n} \ln (\mathrm{b})+\mathrm{n} \ln (\theta)+2 \mathrm{n} \ln (\lambda)+\sum_{\mathrm{i}=1}^{\mathrm{n}} \ln \left(\mathrm{x}_{\mathrm{i}}\right)-\sum_{\mathrm{i}=1}^{\mathrm{n}} \mathrm{z}_{\mathrm{i}}^{2}$

$+(\theta \mathrm{a}-1) \sum_{\mathrm{i}=1}^{\mathrm{n}}\left(\mathrm{w}_{\mathrm{i}}\right)+(\mathrm{b}-1) \sum_{\mathrm{i}=1}^{\mathrm{n}} \ln \left(1-\mathrm{W}_{\mathrm{i}}^{\theta \mathrm{a}}\right)$

Where $Z_{i}=\lambda x_{i} \quad$ ، $\quad D_{i}=e^{-Z_{i}^{2}}$ ، $\quad W_{i}=1-D_{i}$

The score vector is $\mathrm{U}(\beta)=(\partial \mathrm{L} / \partial \mathrm{a}, \partial \mathrm{L} / \partial \mathrm{b}, \partial \mathrm{p} / \partial \theta, \partial \mathrm{L} / \partial \lambda)^{\mathrm{T}}$, where the components corresponding to the parameters in $\beta$ are given by differentiating eq.(24), we obtain

$$
\begin{aligned}
& \frac{\partial \mathrm{L}}{\partial \mathrm{a}}=\frac{\mathrm{n}}{\mathrm{a}}+\theta \sum_{\mathrm{i}=1}^{\mathrm{n}} \ln \left(\mathrm{W}_{\mathrm{i}}\right)-\theta(\mathrm{b}-1) \sum_{\mathrm{i}=1}^{\mathrm{n}} \frac{\mathrm{w}_{\mathrm{i}}^{\theta \mathrm{a}} \ln \left(\mathrm{w}_{\mathrm{i}}\right)}{1-\mathrm{w}_{\mathrm{i}}^{\theta \mathrm{a}}} \\
& \frac{\partial \mathrm{L}}{\partial \mathrm{b}}=\frac{\mathrm{n}}{\mathrm{b}}+\sum_{\mathrm{i}=1}^{\mathrm{n}} \ln \left(1-\mathrm{w}_{\mathrm{i}}^{\theta \mathrm{a}}\right) \\
& \frac{\partial \mathrm{L}}{\partial \theta}=\frac{\mathrm{n}}{\theta}+\mathrm{a} \sum_{\mathrm{i}=1}^{\mathrm{n}} \ln \left(\mathrm{w}_{\mathrm{i}}\right)-\mathrm{a}(\mathrm{b}-1) \sum_{\mathrm{i}=1}^{\mathrm{n}} \frac{\mathrm{w}_{\mathrm{i}}^{\theta a} \ln \left(\mathrm{w}_{\mathrm{i}}\right)}{1-\mathrm{w}_{\mathrm{i}}^{\theta \mathrm{a}}}
\end{aligned}
$$




$$
\frac{\partial \mathrm{L}}{\partial \lambda}=\frac{2 \mathrm{n}}{\lambda}+\frac{2}{\lambda} \sum_{\mathrm{i}=1}^{\mathrm{n}} \mathrm{Z}_{\mathrm{i}}^{2}+\frac{2(\theta \mathrm{a}-1)}{\lambda} \sum_{\mathrm{i}=1}^{\mathrm{n}} \frac{\mathrm{D}_{\mathrm{i}} \mathrm{Z}_{\mathrm{i}}^{2}}{\mathrm{~W}_{\mathrm{i}}}-\frac{2 \theta \mathrm{a}(\mathrm{b}-1)}{\lambda} \sum_{\mathrm{i}=1}^{\mathrm{n}} \frac{\mathrm{Z}_{\mathrm{i}}^{2} \mathrm{D}_{\mathrm{i}} \mathrm{W}^{\theta \mathrm{a}-1}}{1-\mathrm{W}_{\mathrm{i}}^{\theta \mathrm{a}}}
$$

The MLEs of the unknown parameters can be obtained by solving the system for nonlinear equations (25-28) by equating these equations to zero and solve them simultaneously, which are solved iteratively. For interval estimation and hypothesis tests on the model parameters, we require the observed information matrix as follow

$$
\mathrm{J}_{\mathrm{n}}(\beta)=\left[\begin{array}{cccc}
\mathrm{J}_{\mathrm{aa}} & \mathrm{J}_{\mathrm{ab}} & \mathrm{J}_{\mathrm{a} \theta} & \mathrm{J}_{\mathrm{a} \lambda} \\
\mathrm{J}_{\mathrm{ba}} & \mathrm{J}_{\mathrm{bb}} & \mathrm{J}_{\mathrm{b} \theta} & \mathrm{J}_{\mathrm{b} \lambda} \\
\mathrm{J}_{\theta \mathrm{a}} & \mathrm{J}_{\theta \mathrm{b}} & \mathrm{J}_{\theta \theta} & \mathrm{J}_{\theta \lambda} \\
\mathrm{J}_{\lambda \mathrm{a}} & \mathrm{J}_{\lambda \mathrm{b}} & \mathrm{J}_{\lambda \theta} & \mathrm{J}_{\lambda \lambda}
\end{array}\right]
$$

whose elements are

$$
\begin{aligned}
& \mathrm{J}_{\mathrm{aa}}=\frac{-n}{a^{2}}-\theta^{2}(b-1) \sum_{i=1}^{n} \frac{w_{i}^{\theta a}\left(\ln w_{i}\right)^{2}}{\left(1-w_{i}^{\theta a}\right)^{2}}, \quad \mathrm{~J}_{\mathrm{ab}}=-\theta \sum_{i=1}^{n} \frac{w^{\theta a} \ln w_{i}}{1-w_{i}^{\theta a}} \\
& \mathrm{~J}_{\mathrm{a} \theta}=\sum_{i=1}^{n} \ln w_{i}-(b-1) \sum_{i=1}^{n} \frac{w_{i}^{\theta a} \ln w_{i}\left(a \theta \ln w_{i}-w_{i}^{\theta a}+1\right)}{\left(1-w_{i}^{\theta a}\right)^{2}} \\
& \mathrm{~J}_{\mathrm{a} \lambda}=\frac{2 \theta}{\lambda} \sum_{i=1}^{n} \frac{D_{i} Z_{i}^{2}}{W_{i}}-\frac{2 \theta(b-1)}{\lambda} \sum_{i=1}^{n} \frac{w^{\theta a-1} D_{i} Z_{i}^{2}\left(1+a \theta \ln w_{i}-w_{i}^{\theta a}\right)}{\left(1-w_{i}^{\theta a}\right)^{2}} \\
& \mathrm{~J}_{\mathrm{bb}}=\frac{-\mathrm{n}}{\mathrm{b}^{2}} \quad \cdot \quad \mathrm{J}_{\mathrm{b} \theta}=-\mathrm{a} \sum_{i=1}^{n} \frac{w^{\theta a} \ln w_{i}}{1-w_{i}^{\theta a}} \\
& \mathrm{~J}_{\mathrm{b} \lambda}=\frac{-2 \theta \mathrm{a}}{\lambda} \sum_{\mathrm{i}=1}^{\mathrm{n}} \frac{\mathrm{w}_{\mathrm{i}}^{\theta \mathrm{a}-1} \mathrm{D}_{\mathrm{i}} \mathrm{Z}_{\mathrm{i}}^{2}}{1-\mathrm{w}_{\mathrm{i}}^{\theta \mathrm{a}}}, \quad \mathrm{J}_{\theta \theta}=\frac{-n}{\theta^{2}}-a^{2}(b-1) \sum_{i=1}^{n} \frac{w_{i}^{\theta a}\left(\ln w_{i}\right)^{2}}{\left(1-w_{i}^{\theta a}\right)^{2}} \\
& \mathrm{~J}_{\theta \lambda}=\frac{2 a}{\lambda} \sum_{i=1}^{n} \frac{D_{i} Z_{i}^{2}}{W_{i}}-\frac{2 a(b-1)}{\lambda} \sum_{i=1}^{n} \frac{w^{\theta a-1} D_{i} Z_{i}^{2}\left(1+\theta a \operatorname{Ln} w_{i}-w_{i}^{\theta a}\right)}{\left(1-w_{i}^{\theta a}\right)^{2}} \\
& \mathrm{~J}_{\lambda \lambda}=\frac{-2}{\lambda^{2}}+\frac{2}{\lambda^{2}} \sum_{i=1}^{n} Z_{i}^{2}+\frac{2(\theta a-1)}{\lambda^{2}} \sum_{i=1}^{n} Z_{i}^{2} D_{i} A_{1} \\
& -\frac{2 \theta \mathrm{a}(\mathrm{b}-1)}{\lambda^{2}} \sum_{\mathrm{i}=1}^{\mathrm{n}}\left(2 \mathrm{Z}_{\mathrm{i}}^{2} \mathrm{D}_{\mathrm{i}} \mathrm{W}^{2 \theta \mathrm{a}-2} \mathrm{~A}_{2}+\mathrm{D}_{\mathrm{i}} \mathrm{W}_{\mathrm{i}}^{2 \theta \mathrm{a}-1} \mathrm{Z}_{\mathrm{i}}^{2} \mathrm{~A}_{3}\right)
\end{aligned}
$$

where 


$$
\begin{aligned}
& \mathrm{A}_{1}=\left(\mathrm{W}_{\mathrm{i}}-2 \mathrm{~W}_{\mathrm{i}} \mathrm{Z}_{\mathrm{i}}^{2}-2 \mathrm{Z}_{\mathrm{i}}^{2} \mathrm{D}_{\mathrm{i}}\right) / \mathrm{W}_{\mathrm{i}}^{2} \\
& \mathrm{~A}_{2}=1+(\theta \mathrm{a}-1) \mathrm{D}_{\mathrm{i}} \mathrm{W}_{\mathrm{i}}^{-\theta \mathrm{a}} \\
& \mathrm{A}_{3}=2 \mathrm{Z}_{\mathrm{i}}\left(1-\mathrm{W}_{\mathrm{i}}^{-\theta \mathrm{a}}\right)+\left(\mathrm{W}_{\mathrm{i}}^{-\theta \mathrm{a}}-1\right)
\end{aligned}
$$

\subsection{Application}

This section contains an application of the KW-ER distributions to two examples of real data. The first data set extracted from Nichols and Padgett (2006), gives 100 observations on breaking stress of carbon fibers (in Gba): $0.39,0.81,0.85,0.98,1.08,1.12,1.17,1.18,1.22,1.25,1.36,1.41,1.47,1.57,1.57,1.59,1.59$, 1.61, $1.61,1.69,1.69,1.71,1.73,1.80,1.84,1.84,1.87,1.89,1.92,2,2.03,2.03,2.05,2.12,2.17,2.17,2.17,2.35$, $2.38,2.41,2.43,2.48,2.48,2.50,2.53,2.55,2.55,2.56,2.59,2.67,2.73,2.74,2.76,2.77,2.79,2.81,2.81$, $2.82,2.83,2.85,2.87,2.88,2.93,2.95,2.96,2.97,2.97,3.09,3.11,3.11,3.15,3.15,3.19,3.19,3.22,3.22$, $3.27,3.28,3.31,3.31,3.33,3.39,3.39,3.51,3.56,3.60,3.65,3.68,3.68,3.68,3.70,3.75,4.20,4.38,4.42$, 4.70. 4.90, 4.91, 5.08, 5.56. The second data set is obtained from Bader and Priest (1982). The data represent the single Carbon fibers of $10 \mathrm{~mm}$ in gauge length with sample size 63 observations (in GPA): $0.101,0.332$, $0.403,0.428,0.457,0.550,0.561,0.596,0.597,0.645,0.654,0.674,0.718,0.722,0.725,0.732,0.775,0.814$, $0.816,0.818,0.824,0.859,0.875,0.938,0.940,1.056,1.117,1.128,1.137,1.137,1.177,1.196,1.230,1.325$, $1.339,1.345,1.420,1.423,1.435,1.443,1.464,1.472,1.494,1.523,1.564,1.577,1.608,1.635,1.693,1.701$, $1.737,1.754,1.762,1.828,2.052,2.071,2.086,2.171,2.224,2.227,2.425,2.592,3.220$. The required numerical evaluations are implemented using Mathcad Package software. We use the above real data to compare the fits of the proposed model (KW-ER distribution) and those of other sub-models, i.e. the Kumaraswamy Rayleigh (KW-R) distribution and the exponentiated Rayleigh (ER) distribution.

Table (1) gives the MLEs of the model parameters for KW-ER, KW-R, and ER distributions and the values of the Akaike information Criterion (AIC) for the first data set as follows:

Table (1) MLEs of the model parameters for the first data set and AIC statistic

\begin{tabular}{|c|c|c|c|c|c|}
\hline \multirow{2}{*}{ Model } & \multicolumn{4}{|c|}{ Estimates } & \multirow{2}{*}{ AIC } \\
\cline { 2 - 5 } & $\boldsymbol{\lambda}$ & $\boldsymbol{\theta}$ & $\mathbf{a}$ & $\mathbf{b}$ & \\
\hline KW-ER & 0.116 & 0.398 & 0.272 & 0.454 & 556.16 \\
\hline KW-R & 0.0006 & - & 0.212 & 3.209 & 562.998 \\
\hline ER & 0.085 & 1.63 & - & - & 564.606 \\
\hline
\end{tabular}

Table (2) lists the MLEs of the model parameters and the value of (AIC) statistic for the second data set as

\begin{tabular}{|c|c|c|c|c|c|}
\hline \multirow{2}{*}{ Model } & \multicolumn{4}{|c|}{ Estimates } & \multirow{2}{*}{ AIC } \\
\hline & $\lambda$ & $\theta$ & A & b & \\
\hline KW-ER & 0.15 & 0.427 & 0.509 & 0.428 & 270.228 \\
\hline KW-R & 0.121 & - & 0.192 & 0.576 & 277.646 \\
\hline ER & 0.228 & 0.165 & - & - & 281.462 \\
\hline
\end{tabular}
follows:

Table (2) MLEs of the model parameters for the second data set and AIC statistic

Note that $\mathrm{AIC}=-2 \mathrm{~L}+2 \mathrm{q}$, where $\mathrm{L}$ denotes the log-likelihood function evaluated at the maximum likelihood estimates and $\mathrm{q}$ is the number of parameters. From Table (1) and (2), the results indicate that the KW-ER model has the smaller value of (AIC) statistic when compared to that value of the (KW-R) and (ER) models. So, the KW-ER model provides a better fit to these data. 


\section{Conclusion}

In this paper, we have introduced and studied a lifetime distribution, so-called the Kumaraswamy exponentiated rayleigh distribution as a simple extension of the rayleigh and the exponentiated rayleigh distributions. A detailed study on the mathematical properties of the new distribution is presented. The ordinary moments, incomplete moment, the moment generating function, quantile function and skewness and kurtosis measures are discussed and derived. The density function of the order statistics and their moments were provided. An explicit expression for Renyi entropy is studied. Parameters estimation is approached by maximum likelihood and the observed fisher information matrix is derived. Two numerical examples of real data showed that the new model provides better fits than their sub-models.

\section{References}

[1] M.G. Bader and A.M. Priest, Statistical aspects of fiber and bundle strength in hybrid composites, In: Progress in science and engineering composites, T.Hayashi, K.. Kawata and S. Umekawa (eds), ICCM-IV,( Tokyo, 1982).

[2] M.Bourguignon, R.B.Silva, L.M. Zea and G.M. Cordeiro, The Kumaraswamy Parato distribution, Journal of statistical theory and applications, 12(2012), 129-144.

[3] G.Brys, M. Hubert and F.A.Struy, Robust measures of tail weight, Computational statistics and data analysis, 50(2006), 733759.

[4] I.W. Burr, Cumulative Frequency distribution", Annals of Mathematical statistics,13(1942), 215-232.

[5] M.F. Carrasco, S.L Ferrari and G.M. Cordeiro, (2010) "A new generalized Kumaraswamy distribution", arxiv: 1004.09 IIVI (Stat. ME), 17(2010).

[6] G.M. Cordeiro, and M. deCastro, A new family of generalized Distribution, Journal of Statistical Computation and Simulation, 81(2010), 883:898.

[7] G.M. Cordeiro, A.C. Junior, C.G. Demetrio, E.M. Ortega, and R.R. Pescim, Some new results for the Kumaraswamy modified weibull distribution", Journal of Statistical Theory and applications, 13(2014),86-104.

[8] G.M Cordeiro, E.M. Ortega, and S. Nadarajah, The Kumaraswamy weibull distribution with application to failure data, Journal of the Franklin institute, 347(2010), 1399-1429.

[9] G.M. Cordeiro R.Pescim and E.M. Ortega,The Kumaraswamy Generalized half-normal distribution for skewed positive data, $J$. Data Sci.,10(2012),195-224.

[10] I. El-Batal and A. Kareem, Statistical Properties of Kumaraswamy exponentiated lomax distribution, Journal of modern Mathematics and statistics, 8(2014), 1-7.

[11] M.C. Jones, A beta-type distribution with some tractability advantages, Statistical Methodology, 6(2009), 70:81.

[12] J.F. Kenny and E.S Keeping, Mathematics of statistics. Part 1, Van Nostrand (.New Jersey1962)

[13] P. Kumaraswamy, Generalized probability density function for double-bounded random processes", Journal of hydrology, 46(1980),79:88.

[14] D. Kundu, and M.Z Ragab, Generalized rayleigh distribution: different methods of estimation, Computational statistics and data analysis, 49(2005), 187-200.

[15] J.J Moors, A quantile alternative for kurtosis, Journal of the royal statistical society, 371980),25-32.

[16] M.D. Nichols and W.J. Padgett , A bootstrap Control chart for weibull percentiles, Quality and reliability engineering international, 22(2006), 141:151.

[17] M.A. Pascoa, E.M. Ortega, and G.M. Cordeiro, The Kumaraswamy generalized gamma distribution with application in survival analysis, Stat. Method., 8(2011),411-433.

[18] M.Z. Ragab, Order statistics from the Burr X model , Computer Mathematics and applications, 36(1998), 111-120.

[19] M.Z. Ragab, and M.T. Madi, Bayesian analysis for the exponentiated rayleigh distribution", Metron-international Journal of statistics Vol. LXV II, 3(2009),269-288.

[20] H.A. Sartawi and M.S. Abu-Salih, Bayes Prediction bounds for the Burr X model, Communications in statistics-Theory and Methods, 20(1991), 2307-2330.

[21] E. Seier, and D. Bonett, Two families of Kurtosis measures, Metrika,58(2003), 59-70.

[22] S.K. Shankar and V. Kumar, Bayesian analysis for the generalized rayleigh distribution", International Journal of Statistika and Mathmatika, 9(2014), 118-131.

[23] J.G. Surless and W.J. Padgett, Some Properties of a scaled Burr type X distribution, Journal of statistical planning and inference, 128(2005), 271-280.

[24] M.H. Tahir, G.M. Cordeiro, M. Mansoor, and M. Zubair, The weibull-Lomax distribution: Properties and applications, Hacettepe University Bulletin of Natural Sciences and engineering series B: Mathematics and statistics (HACETJ MATH STAT). 5(2014), Dol:10.15672/HJMS.2014147465.

[25] V.G. Voda, A new generalization of rayleigh distribution" Reliability: Theory and applications, 2(2007),47-56. 